\title{
COVID-19 expands food insecurity disparities among rural, high-risk obstetrics patients
}

\author{
Ailynna Chen, ${ }^{1}$ Katherine Merritt, ${ }^{1}$ Anna Greenwood, ${ }^{1}$ Craig H. Syrop, ${ }^{2}$ Michael L. \\ Haugsdal $^{2}$
}

Keywords: High-risk obstetrics, food insecurity, COVID-19, health disparity, rural health

\begin{abstract}
Objective: To compare rural and urban food insecurity in a high-risk obstetrics population prior to and during the COVID-19 pandemic.

Methods: Utilizing convenience sampling of high-risk obstetrics patients, validated survey questions assessed self-reported food insecurity from March - October 2019 (pre-COVID-19) and March - October 2020 (COVID-19). Chi-squared analysis compared food insecurity between these two periods and among patients living in rural vs. urban counties.
\end{abstract}

Results: A total of 1089 (pre-COVID-19) and 1246 (COVID-19) screenings were completed. Compared to 2019, the prevalence of food insecurity in 2020 was significantly higher from March-June only (7.8\% pre-COVID-19 vs. 11.4 $\%$ COVID-19, $p=0.04)$. Despite pre-COVID-19 similarity, rural patients reported significantly higher food insecurity prevalence during COVID19 than urban counterparts (12.9\% rural vs. $8.2 \%$ urban, $p<0.01)$.

Conclusions: The COVID-19 pandemic was associated with a disproportionate effect on food insecurity among rural patients with high-risk pregnancies. Rural health systems and agencies should explore proactive screening and intervention efforts to mitigate the adverse, downstream health effects of food insecurity.

1 University of lowa Carver College of Medicine, lowa City, lowa

${ }^{2}$ University of lowa Hospitals and Clinics, Department of Obstetrics and Gynecology, lowa City, lowa

\section{Introduction}

Food insecurity is a social determinant of health associated with higher risks of many chronic conditions including diabetes, cardiovascular disease, mental health disorders, as well as higher annual healthcare expenditures. ${ }^{1,2}$ Among obstetrics patients, food insecurity is associated with adverse pregnancy outcomes including preterm birth, low birthweight, and gestational diabetes. ${ }^{3}$

Rural, non-metropolitan communities

Please cite this paper as: Chen A, Merritt K, Greenwood A, Syrop CH, Haugsdal ML. COVID-19 expands food insecurity disparities among rural, high-risk obstetrics patients. Proc Obstet Gynecol. 2022;11(1):Article 1 [ 10 p.]. Available from: https://pubs.lib.uiowa.edu Free full text article.

Corresponding author: Michael L. Haugsdal, MD, Department of Obstetrics and Gynecology, University of lowa, lowa City, IA, michael-haugsdal@uiowa.edu

Financial Disclosure: The authors report no conflict of interest.

Copyright: @ 2022 Chen et al. This is an open-access article distributed under the terms of the Creative Commons Attribution License, which permits unrestricted use, distribution, and reproduction in any medium, provided the original author and source are credited. 
have traditionally experienced higher levels of food insecurity than urban counterparts. According to the 2012 United States Department of Agriculture (USDA) report, the prevalence of food insecurity was $15.5 \%$ among nonmetropolitan households compared to $14.3 \%$ among metropolitan households. ${ }^{4}$ In addition, non-metropolitan households also reported higher rates of poverty, underemployment and unemployment, and decreased access to resources such as grocery stores and public transportation. ${ }^{4,5}$ These factors may increase the vulnerability of rural populations to the effects of public health crises, such as the COVID-19 pandemic.

Recent data suggest that food insecurity in the US increased during the COVID19 pandemic. According to America's Health Rankings in 2019, $12.3 \%$ of US citizens reported being food insecure with rural populations experiencing higher rates of food insecurity. ${ }^{6}$ During March-April 2020, estimates of food insecurity more than tripled (38.3\%) at the national level. ${ }^{7}$ In lowa, the estimated food insecurity prevalence increased from $10.5 \%$ in 2019 to $24.5 \%$ in March-April 2020.6,7 Considering the numerous adverse effects of food insecurity on pregnancy and health outcomes, it is important that we examine and identify the effect of COVID-19 on food insecurity in vulnerable populations, including highrisk obstetrics (HROB) patients and rural communities.

This study aims to characterize the prevalence of food insecurity in a highrisk obstetrics (HROB) population prior to and during the COVID-19 pandemic across rural and urban counties in lowa. Compared to 2019, we hypothesized there would be a significant increase in self-reported food insecurity among HROB patients during the COVID-19 pandemic with rural patients experiencing higher levels of food insecurity than their urban counterparts.

\section{Methods}

This observational study compared the prevalence of self-reported food insecurity in a HROB population prior to and during the COVID-19 pandemic. As part of a quality improvement initiative screening for food insecurity (IRB research-exempt ID: 201807759), convenience sampling was performed for all patients with high-risk pregnancies attending prenatal visits at an academic medical center in lowa, USA between two separate data collection periods of March - October 2019 (pre-COVID-19) and March October 2020 (COVID-19). Patients who attended an appointment in the HROB clinic were given a paper screening form by the medical assistant as they were brought to their clinical exam room. Patients ultimately had the choice whether to complete the screening form. Partially completed screenings were not included in analysis. Survey response rate was determined as the number of screenings completed per number of patient visits during that time. Patients were also asked to include their current county of residence on the form, and surveys were linked to the individual patient by medical record number (MRN) and date of appointment. 
Screening surveys contained two validated food insecurity questions from the Health Leads Social Needs Screening Toolkit. ${ }^{8}$

1. Question \#1: In the last 12 months, did you ever worry that you wouldn't have enough food or money for food for you or your family?

2. Question \#2: Would you like help getting healthy food for you or your family?

An affirmative response to either question categorized the patient as food insecure at that appointment. Selfreported food insecurity was assessed at all (initial and successive) prenatal appointments. As the experience of food insecurity is variable across time, each appointment served as a data point (n) regardless of prior surveys completed by the same patient.

All data were entered into a secure REDCap database and demographic data for each screening survey was extracted from the electronic medical record by matching MRN and date of appointment. Demographic data obtained included age at appointment, marital status, race, ethnicity, insurance type, and preferred language. If patients omitted their county of residence on the initial survey, this information was also obtained.

Data were stratified by rurality of a patient's home county. Rurality delineations were based on the federal Office of Management and Budget (OMB) which broadly defines counties in metropolitan areas as urban and all other counties, including those in micropolitan areas or outside of these two specified areas, as rural. ${ }^{9}$ Patient's home counties were then determined urban or rural according to the 2013 OMB Metropolitan and Micropolitan Statistical Areas. Additionally, data from March - October 2020 (COVID-19) timeframe were grouped for further analysis by early and late pandemic as defined by March - June and July October 2020, respectively.

Statistical analysis was completed using SAS ${ }^{\circledR}$ University Edition (v9.4). Chisquared analysis compared the preCOVID-19 vs. COVID-19 prevalence of food insecurity 1) during early pandemic, late pandemic, and bimonthly; 2) among patients living in rural and urban counties. Statistical significance was determined using $\alpha=0.05$ for all analyses.

\section{Results}

A total of 1089 (pre-COVID-19) and 1246 (COVID-19) screenings were included for analyses, representing response rates of $72.0 \%$ and $79.1 \%$, respectively. On average, each patient was screened 3.1 times pre-COVID-19 and 3.3 times during the COVID-19 timeframe.

Demographic data (Table 1) demonstrates that most surveys were completed by participants between 20$29(45.7 \%)$ and $30-39(47.1 \%)$ years of age. Sixty-two percent of the respondents were married or had a life partner. Seventy-seven percent of the respondents self-identified as White, 
$12.2 \%$ African American/Black, and $6.2 \%$ Hispanic/Latino. English was the most common preferred language
(97.4\%). Majority of the respondents had commercial $(55.5 \%)$ or government insurance (43.9\%).

Table 1. Descriptive characteristics of study population

\begin{tabular}{|c|c|c|}
\hline Variable & Category & Total N (\%) $(n=2335)$ \\
\hline \multirow[t]{5}{*}{ Age } & $<20$ & $81(3.5 \%)$ \\
\hline & $20-29$ & $1066(45.7 \%)$ \\
\hline & $30-39$ & $1099(47.1 \%)$ \\
\hline & $40+$ & $83(3.6 \%)$ \\
\hline & Unknown & $6(0.3 \%)$ \\
\hline \multirow[t]{4}{*}{ Marital Status } & Married/Life Partner & $1458(62.4 \%)$ \\
\hline & Single & $801(34.3 \%)$ \\
\hline & Separated/Divorced/Widowed & $65(2.8 \%)$ \\
\hline & Unknown & $11(0.5 \%)$ \\
\hline \multirow[t]{7}{*}{ Race } & White & $1978(77.0 \%)$ \\
\hline & Hispanic/Latino & $144(6.17 \%)$ \\
\hline & African American/Black & $284(12.2 \%)$ \\
\hline & Asian & $30(1.3 \%)$ \\
\hline & Multiracial & $39(1.7 \%)$ \\
\hline & Other & $17(0.7 \%)$ \\
\hline & Unknown & $23(1.0 \%)$ \\
\hline \multirow[t]{3}{*}{ Ethnicity } & Non-Hispanic & $2127(91.1 \%)$ \\
\hline & Hispanic & $173(7.4 \%)$ \\
\hline & Unknown & $35(1.5 \%)$ \\
\hline \multirow[t]{4}{*}{ Insurance } & Commercial & $1295(55.5 \%)$ \\
\hline & Government $^{1}$ & $1025(43.9 \%)$ \\
\hline & None & $9(0.4 \%)$ \\
\hline & Unknown & $6(0.3 \%)$ \\
\hline \multirow[t]{5}{*}{ Preferred Language } & English & $2274(97.4 \%)$ \\
\hline & Spanish & $18(0.8 \%)$ \\
\hline & French & $13(0.6 \%)$ \\
\hline & Other & $24(1.0 \%)$ \\
\hline & Unknown & $6(0.3 \%)$ \\
\hline \multirow[t]{2}{*}{ County } & Urban & $1337(57.3 \%)$ \\
\hline & Rural & $998(42.7 \%)$ \\
\hline
\end{tabular}

${ }^{1}$ Goverment insurance includes Medicare, Medicaid, and Tricare

As shown in Table 2, food insecurity was significantly higher during the early pandemic from March - June 2020 (11.4\%) compared to March - June
$2019(7.8 \%, p=0.04)$. Similar levels of food insecurity were reported from July - October $(p=0.36)$ and over the entire study period from March - October 
$(p=0.42)$.

Table 2. Results of pre-COVID-19 vs COVID-19 food insecurity screenings in highrisk pregnancies by rurality and pandemic time frame

\begin{tabular}{|c|c|c|c|c|}
\hline & $\begin{array}{c}\text { Total } \\
\text { n }\end{array}$ & $\begin{array}{c}\text { Pre-COVID-19 } \\
n=1089\end{array}$ & $\begin{array}{c}\text { COVID-19 } \\
\mathrm{n}=1246\end{array}$ & $\begin{array}{c}\chi^{2} \text { statistic } \\
(p \text {-value })^{I}\end{array}$ \\
\hline Rural County & 998 & $42(9.2 \%)$ & $70(12.9 \%)$ & $3.41(0.06)$ \\
\hline Urban County & 1337 & $59(9.3 \%)$ & $58(8.2 \%)$ & $0.49(0.48)$ \\
\hline Mar-June & 1185 & $41(7.8 \%)$ & $75(11.4 \%)$ & $4.18(0.04)^{*}$ \\
\hline July - Oct & 1150 & $60(10.6 \%)$ & $53(9.0 \%)$ & $0.82(0.36)$ \\
\hline Mar - Oct & 2335 & $101(9.3 \%)$ & $128(10.3 \%)$ & $0.65(0.42)$ \\
\hline
\end{tabular}

${ }^{1} X^{2}$ test for prevalence of positive screening for food insecurity Pre-COVID vs. COVID.

${ }^{*}$ Denotes statistical significance at the $0.05 \alpha$-level.

Data collected was representative of a total of 57 counties with $42.7 \%$ of screening forms filled out by participants from rural counties. Although greater reporting of food insecurity for rural patients was not observed during the
pre-COVID-19 period $(\mathrm{p}=0.48)$, reporting of food insecurity was significantly higher among rural patients during the COVID-19 period compared to their urban counterparts as shown in Table 3 $(12.9 \%$ vs. $8.2 \%, p<0.01)$.

Table 3. Results of Rural vs Urban County food insecurity screenings in high-risk pregnancies during Pre-COVID-19 and COVID-19 periods

\begin{tabular}{lcccc}
\hline & $\begin{array}{c}\text { Total } \\
\mathbf{n}\end{array}$ & $\begin{array}{c}\text { Rural County } \\
\mathbf{n = 9 9 8}\end{array}$ & $\begin{array}{c}\text { Urban County } \\
\mathbf{n = 1 3 3 7}\end{array}$ & $\begin{array}{c}\boldsymbol{\chi} \mathbf{2} \text { statistic } \\
\text { (p-value) }\end{array}$ \\
\hline Pre-COVID-19 & 1089 & $42(9.2 \%)$ & $59(9.3 \%)$ & $<0.01(0.95)$ \\
COVID-19 & 1246 & $70(12.9 \%)$ & $58(8.2 \%)$ & $7.27(<0.01)^{*}$
\end{tabular}

${ }^{1} X^{2}$ test for prevalence of positive screening for food insecurity in Rural vs. Urban counties.

These findings remained consistent when analyzed at two-month intervals from March - October in both 2019 and 2020 (Figure 1 and Table 4). The prevalence of self-reported food insecurity during COVID-19 in urban counties closely mirrored that of preCOVID-19 at each 2-month interval (Figure 1a) but remained consistently higher throughout the COVID-19 period compared to pre-COVID-19 among rural patients (Figure 1b). 


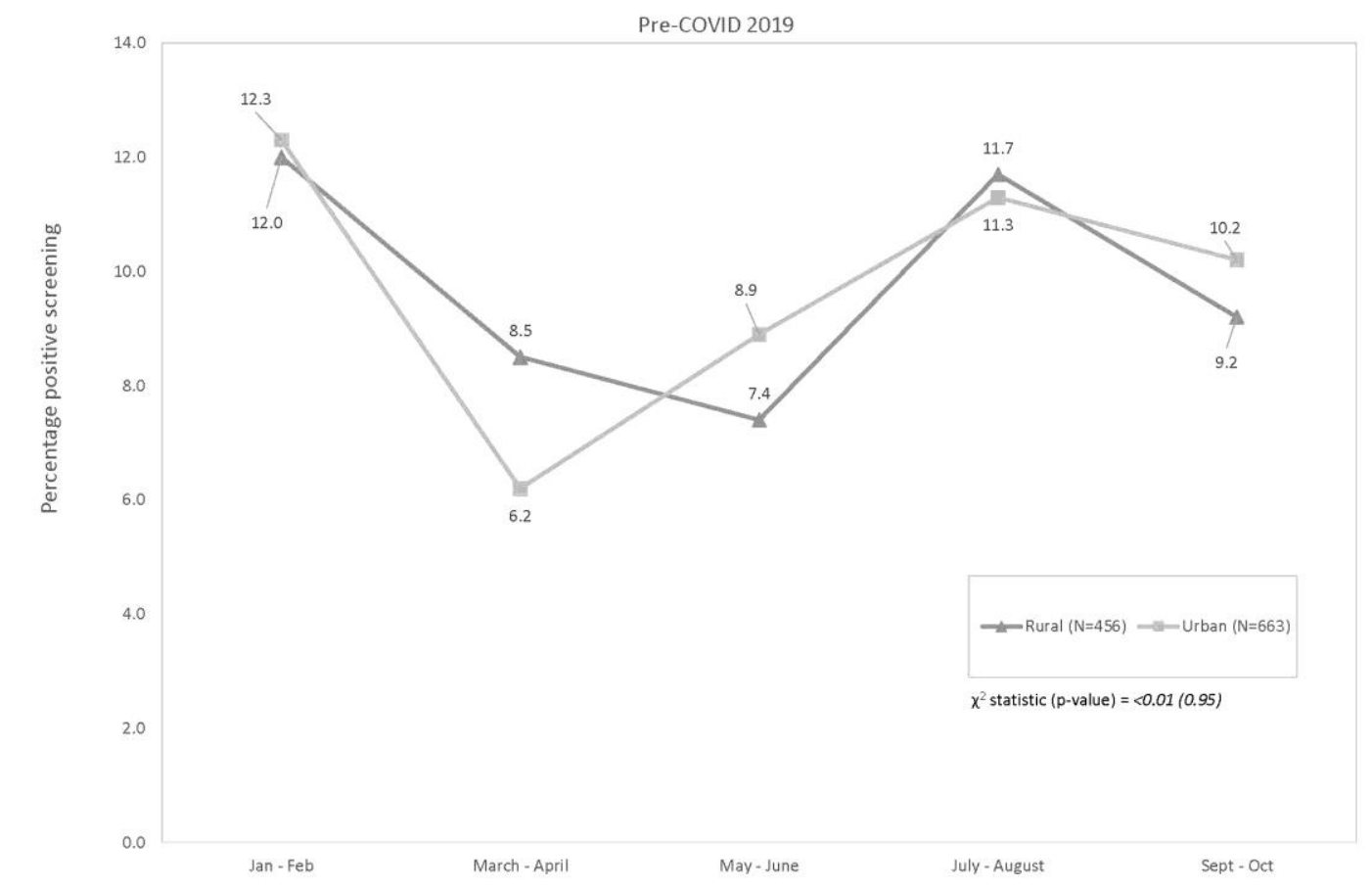

Figure 1(a). Bimonthly comparison of self-reported food insecurity in rural and urban counties during pre-COVID-19. The bimonthly percentage of positive screening for food insecurity in rural counties are similar to that of urban counties during Pre-COVID-19 throughout the study period $(\mathrm{p}=0.95)$.

Table 4. Bimonthly prevalence of positive screening for food insecurity in rural vs. urban counties Pre-COVID 2019 and during COVID 2020.

\begin{tabular}{lcccccc}
\hline \multicolumn{3}{c}{ Pre-COVID-19 } & \multicolumn{5}{c}{ COVID-19 } \\
\hline Months & Total & Rural & Urban & Total & Rural & Urban \\
\hline Jan-Feb & & $\mathrm{n}-456$ & $\mathrm{~N}=663$ & & $\mathrm{~N}=542$ & $\mathrm{~N}=7-4$ \\
\hline Mar-Apr & 189 & $9(12.0)$ & $14(12.3)$ & 314 & $11(8.4)$ & $22(12.0)$ \\
\hline May-June & 236 & $9(8.5)$ & $8(6.2)$ & 341 & $19(14.5)$ & $22(10.5)$ \\
\hline July-Aug & 289 & $9(7.4)$ & $14(8.9)$ & 319 & $19(13.2)$ & $15(8.6)$ \\
\hline Sept-Oct & 288 & $14(11.7)$ & $19(11.3)$ & 298 & $18(12.4)$ & $12(7.8)$ \\
\hline $\begin{array}{l}\text { 2 } \text { statistic } \\
\text { (p-value)1 }\end{array}$ & 276 & $10(9.2)$ & $17(10.2)$ & 288 & $14(11.5)$ & $9(5.4)$ \\
\hline
\end{tabular}

Table 4 contains data graphed in Figure 1.

$1 \times 2$ test for prevalence of positive screening for food insecurity in Rural vs. Urban counties.

${ }^{*}$ Denotes statistical significance at the $0.05 \alpha$-level. 


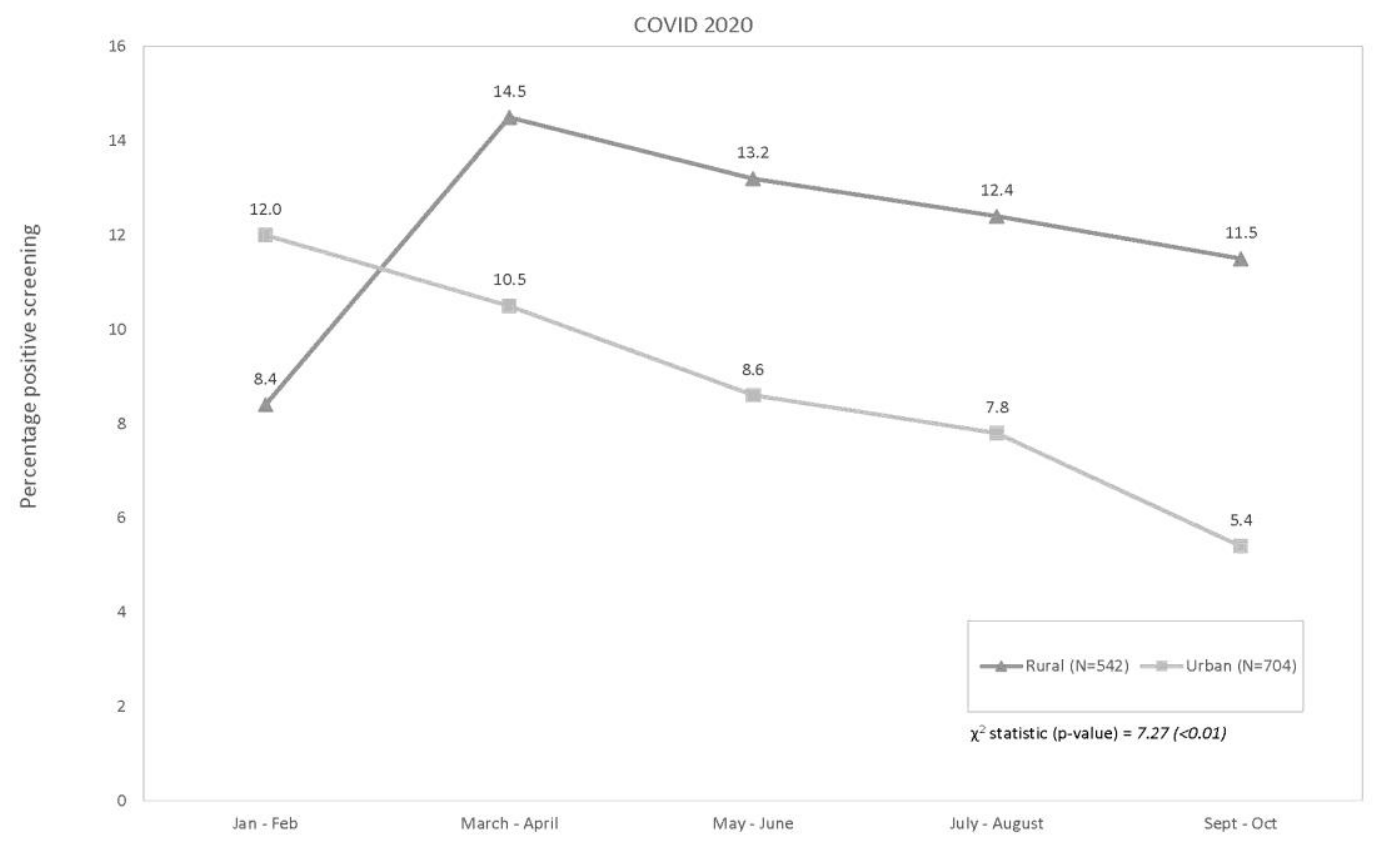

Figure 1(b). Bimonthly comparison of self-reported food insecurity in rural and urban counties during COVID-19. The bimonthly percentage of positive screening for food insecurity in rural counties remained higher than that of urban counties during COVID-19 from March-April through Sept-Oct $(\mathrm{p}<0.01)$.

\section{Discussion}

We observed greater reporting of food insecurity among all HROB patients during the early pandemic. However, as a uniquely vulnerable population, rural patients continued to experience higher levels of food insecurity than urban counterparts throughout the entire COVID-19 study period.

The acute increase in food insecurity (March - June 2020) is consistent with trends reported in the literature. Nationally, results from the COVID Impact Survey show the prevalence of food insecurity in households with children was three times higher in April
2020 than the predicted average from the past 7 years. ${ }^{10}$ Compared to other studies, our observed lower increase and absolute prevalence of food insecurity may be attributable to serial screening at successive visits and the quality improvement initiative's actions of actively referring patients to food resources.

There is limited outside information available on food insecurity prevalence for July - October 2020. However, the subsequent narrowing of our initially observed overall increased food insecurity gap may be explained by the beginning of economic recovery and 
relief actions taken at the State and Federal levels. The federal unemployment rate, a key predictor of food insecurity, peaked at $14.7 \%$ in April 2020 followed by steady decline to $6.7 \%$ in November 2020.11 In mid-April, a stimulus payment was issued followed by the reopening of businesses in most lowa counties in early May. ${ }^{12}$ Other relief efforts during this time included expansion of the Supplemental Nutrition Assistance Program, establishment of the Pandemic Electronic Benefit Transfer program which provided grocery vouchers to families with school children, and initiation of the Families First Coronavirus Response Act. ${ }^{13}$

Rural U.S. households have historically experienced more food insecurity due to lower wages and decreased resource access. ${ }^{14}$ Our study found that during the pre-COVID-19 period, rural HROB patients reported similar levels of food insecurity as their urban counterparts but then reported consistently higher levels throughout the COVID-19 period (March - October 2020). This suggests that rural residents without apparent disadvantages in resource access or economic stability may be more vulnerable to the impacts of adverse public health events and face additional barriers to socioeconomic recovery. One such barrier may be the urban bias of data collection and limited information on the effects of the pandemic in rural communities. ${ }^{15}$ As speculated by Mueller et al., and suggested by our findings, this information gap may lead to recovery policies and relief efforts that are ineffective for rural residents. ${ }^{15}$ Other potential barriers to pandemic recovery in rural regions include limited access to healthcare, transportation, broadband internet, and an economic reliance on industries more susceptible to person-to-person viral transmission and pandemic-related closures. ${ }^{15-17}$

Our study had the following limitations. First, as an observational study, it is only able to demonstrate an association between the COVID-19 pandemic and increase in self-reported food insecurity. Due to multifocal demands in a busy clinical setting and the requirement of patient participation in obtaining proper screening data, screenings were not completed for all appointments. This introduces potential selection bias as food insecurity may not be something that the patient feels comfortable discussing in this setting. Likewise, stigma related to food insecurity may lead to underreporting amongst our patients. Finally, lowa's geographic and population demographics may limit the generalizability of our findings to other populations.

In conclusion, this study extends characterization of COVID-19 as an "acute crisis with long-term health implications"13 requiring immediate consideration and intervention for a vulnerable population where limited data is available. Other literature has reported an initial increase in overall food insecurity at the beginning of the pandemic. ${ }^{7,10}$ Our findings show that despite pandemic relief efforts, residents of rural counties continued to self-report higher levels of food insecurity into the later pandemic period than urban residents. 


\section{Public Health Implications}

Our study highlights how public health emergencies can acutely exacerbate social determinants of health needs in vulnerable populations. Rural high-risk obstetrics patients continued to report higher levels of food insecurity despite pandemic relief measures and nationally declining unemployment rates. ${ }^{11,}{ }^{13}$ Rural health systems and agencies should consider the impact of this pandemic on food insecurity, its downstream health implications, and appropriate community-based interventions. To formulate better longterm recovery plans for rural communities, further research is needed to reveal the factors that increase or prolong rural residents' vulnerability to pandemic-related impacts.

\section{References}

1. Gundersen C, Ziliak JP. Food Insecurity And Health Outcomes. Health Aff (Millwood). 2015 Nov;34(11):1830-9. https://doi.org/10.1377/hlthaff.2015.0645 . PMID: 26526240.

2. Berkowitz SA, Basu S, Gundersen C, Seligman HK. State-Level and CountyLevel Estimates of Health Care Costs Associated with Food Insecurity. Prev Chronic Dis. 2019 Jul 11;16:E90. https://doi.org/10.5888/pcd16.180549.

PMID: $\quad 31298210$; PMCID: PMC6741857.

3. Ivers LC, Cullen KA. Food insecurity: special considerations for women. Am J Clin Nutr. 2011 Dec;94(6):1740S1744S.

https://doi.org/10.3945/ajcn.111.012617. Epub 2011 Nov 16. PMID: 22089447; PMCID: PMC3226027.
4. Piontak JR, Schulman MD. Food insecurity in rural America. Contexts. 2014;13(3):75-77. doi: $10.1177 / 1536504214545766$.

https://journals.sagepub.com/doi/full/10. 1177/1536504214545766

5. Coleman-Jensen, A, Nord A, Singh A. Household Food Security in the United States in 2012, ERR-155, U.S. Department of Agriculture, Economic Research Service, September 2013. https://www.ers.usda.gov/webdocs/publi cations/45129/39937 err-155.pdf

6. America's Health Rankings. Analysis of U.S. Department of Agriculture, Household Food Security in the United States Report, United Health Foundation. 2021. Accessed January 5, 2021.

https://www.americashealthrankings.org

7. Fitzpatrick K, Harris C, Drawve G. Assessing U.S. food insecurity in the United States during COVID-19 pandemic. 2020. Accessed January 5, 2021. https://www.cresp.udel.edu/wpcontent/uploads/2020/05/AssessingFood-Insecurity-Brief.pdf

8. Health Leads. Social Needs Screening Toolkit. Published July, 2016. Available at:

http://www.nysafp.org/NYSAFP/media/P DFs/Leadership\%20Minutes/10-HealthLeads-Social-Needs-Screening-ToolkitJuly-2016.pdf. Accessed March 7, 2021.

9. Defining rural population. Official web site of the U.S. Health Resources \& Services Administration. https://www.hrsa.gov/rural-health/aboutus/definition/index.html. Published October 5, 2021. Accessed December 19, 2021. 
10. Schanzenbach, DW, Pitts A. Estimates of food insecurity during the COVID-19 crisis: Results from the COVID Impact Survey, Week 1 (April 20-26, 2020). Institute for Policy Research Rapid Research Report. Published May 18, 2020. Accessed January 20, 2021. https://www.ipr.northwestern.edu/docum ents/reports/food-insecuritycovid week1 report-13-may-2020.pdf

11. U.S. Congressional Research Service. Unemployment rates during the COVID19 pandemic: in brief. R46554. Updated January 12, 2021. Accessed January 20, 2021. https://fas.org/sgp/crs/misc/R46554.pdf

12. Documenting lowa's path to recovery from the coronavirus (COVID-19) pandemic, 2020-2021. Ballotpedia. Accessed January 24, 2021. https://ballotpedia.org/Documenting low a\%27s path to recovery from the cor onavirus (COVID-19) pandemic, 2020$\underline{2021}$

13. Wolfson JA, Leung CW. Food Insecurity During COVID-19: An Acute Crisis With Long-Term Health Implications. Am J Public Health. 2020 Dec;110(12):17631765.

https://doi.org/10.2105/AJPH.2020.3059 53. Epub 2020 Sep 24. PMID: 32970451; PMCID: PMC7662000.
14. FRAC. Rural hunger in America. Food Research \& Action Center. 2021. Accessed January 5, 2021. https://frac.org/hunger-povertyamerica/rural-

hunger\#: :text $=16.5 \% 25 \% 20$ of\%20rural $\% 20$ households $\% 20$ faced,outcomes $\% 2$ 0than\%20their\%20urban\%20counterpar ts.

15. Mueller JT, McConnell K, Burow PB, Pofahl K, Merdjanoff AA, Farrell J. Impacts of the COVID-19 pandemic on rural America. Proc Natl Acad Sci U S A. 2021 Jan 5;118(1):2019378118. https://doi.org/10.1073/pnas.201937811 8. PMID: 33328335; PMCID: PMC7817144.

16. Perrin A. Digital gap between rural and nonrural American persists. Pew Research Center. Published May 31, 2019. Accessed January 20, 2021. https://www. pewresearch.org/facttank/2019/05/31/digital-gap-betweenrural-and-nonrural-america-persists/.

17. Del Rio M, Hargrove WL, Tomaka J, Korc M. Transportation Matters: A Health Impact Assessment in Rural New Mexico. Int J Environ Res Public Health. 2017 Jun 13;14(6):629. https://doi.org/10.3390/ijerph14060629. PMID: 28608826; PMCID: PMC5486315. 